\title{
CORE KNOWLEDGE OR LANGUAGE-AUGMENTED COGNITION? THE CASE OF GEOMETRIC REASONING
}

\author{
GARY LUPYAN ${ }^{* 1}$, ASHLEY WENDORF $^{1}$, LUIS MIGUEL BERSCIA $^{2}{ }^{2}$ JING PAUL $^{3}$ \\ *Corresponding Author: lupyan@wisc.edu \\ ${ }^{1-2}$ Department of Psychology, University of Wisconsin-Madison, USA \\ ${ }^{3}$ Radboud University; MPI for Psycholinguistics, Nijmegen, Netherlands \\ ${ }^{4}$ Other Department, Agnes Scott College, Decateur, GA USA
}

Understanding why language evolved in the hominid lineage requires understanding both the communicative as well as the cognitive functions of language. To what extent does language enable certain cognitive operations? What aspects of what we take to be 'normal' human cognition are enabled or facilitated by language? Some have argued that the answer is essentially 'none', and that while language is important for sharing and thereby accumulating cultural knowledge, our core cognitive processes are language-independent (e.g., Bloom \& Keil, 2001; Gleitman \& Fisher, 2005; Hespos \& Spelke, 2004). Indeed, a dominant position within cognitive science posits that it is because humans are endowed with certain cognitive powers such as systematicity and symbolic reasoning that language learning and use is possible in the first place (e.g., Fodor, 2001; Laurence \& Margolis, 1999).

On an alternate view, human cognition is transformed by the learning and use of a natural language (Bowerman \& Levinson, 2001; Clark, 1998; Lupyan, 2012). In particular, language has been argued to be centrally involved in "nonverbal" tasks that require grouping together diverse exemplars based on specific criteria (Lupyan, 2009) - an essential component of symbolic thought. To the extent that this alternate view is correct, theories of language evolution need to expand their focus beyond the use of language for communication.

In this work we provide a strong test for the involvement of language in reasoning by examining geometric reasoning, a domain claimed to tap into a universal and language-independent human competence. Key evidence in support of universality and language-independence of geometric reasoning comes from a study by Dehaene et al. (2006) showing a strong correlation in performance on an odd-one-out geometric reasoning task between educated Americans and the Mundurukú, an Amazonian indigenous people without formal education and who do not possess vocabulary for describing the geometric relations in question.

We tested for causal involvement of language in geometric reasoning in six ways: (1) We examined whether overtly naming geometric relations improved 
reasoning performance in English-speaking adults. (2) We examined whether interfering with language (having participants repeat " $a \mathrm{~b} c$ " while doing the task for some trials) impaired performance. (3) We tested whether the ease of naming the relations in English selectively predicts English-speakers performance. (4) We tested whether ease of naming predicted the detrimental impact of verbal interference. (5) We tested congenitally deaf children residing in a Chinese special school for the deaf who were deprived of normal language input for most of their childhood, and compared their performance to children with normal language input and Chinese adults. (6) We collected data on the task from the Shawi, an indigenous group of horticulturalist traders from Northwestern Amazonia who speak a Kawapanan language. The Shawi we tested vary in formal education and knowledge of Spanish.

Our results replicate Dehaene et al's (2006) finding of substantial correlations in performance $(r>.6)$ even among these very disparate populations. However, these correlations appear to reflect shared visual processing mechanisms rather than shared geometric reasoning abilities. We found strong evidence of causal involvement of language as revealed by: (1) overt naming improving performance $(t=3.7)$, (2) verbal interference impairing performance $(t=2.76)$, (3) significant correlations between performance and nameability $(r>.5)$. (4) The effects of linguistic manipulations dependent on nameability: overt naming raised performance hard-to-name items $(r=-.37)$; verbal interference selectively impaired performance on the normally easy-to-name items $(r=.35)$. (5) Children with impaired language input performed substantially worse $(M=.50)$ than children with normal language input $(M=.75$; $t=4.1)$. The performance of the former was predicted by proficiency with Chinese sign language. (6) The Shawi performed poorly $(M=.41)$ though, like the Mundurukú, considerably above chance (chance=.17). The Shawi's performance was strongly modulated by knowledge of Spanish. Importantly, neither the Mundurukú's nor the Shawi's responses were predicted by either English or Chinese nameability, suggesting that geometric relations that are easy to name are not universally accessible, but become easy when compact verbal descriptions are available.

Language may facilitate geometric reasoning by helping to construct a more categorical hypothesis space. Faced with an array of objects, the ability to name the objects and their relations (e.g., square, parallel, right-angle) provides an effective means of abstracting away perceptual factors that otherwise dominate the categorization response. The implications of this work reach beyond geometry showing how aspects of cognition frequently claimed to nonlinguistic in fact depend on linguistic enculturation and active language use. 


\section{References}

Bloom, P., \& Keil, F. C. (2001). Thinking through language. Mind \& Language, 16(4), 351-367.

Bowerman, M., \& Levinson, S. C. (2001). Introduction. In M. Bowerman \& S. C. Levinson (Eds.), Language acquisition and conceptual development (pp. 1-16). Cambridge, UK: Cambridge University Press.

Clark, A. (1998). Magic words: How language augments human computation. In P. Carruthers \& J. Boucher (Eds.), Language and Thought: Interdisciplinary themes (pp. 162-183). New York, NY: Cambridge University Press.

Dehaene, S., Izard, V., Pica, P., \& Spelke, E. S. (2006). Core Knowledge of Geometry in an Amazonian Indigene Group. Science, 311(5759), 381-384. https://doi.org/10.1126/science.1121739

Fodor, J. A. (2001). Language, Thought and Compositionality. Mind \& Language, 16(1), 1-15. https://doi.org/10.1111/1468-0017.00153

Gleitman, L., \& Fisher, C. (2005). Universal aspects of word learning. In J. McGilvray (Ed.), The Cambridge Companion to Chomsky (pp. 123-144). New York, NY: Cambridge University Press. Retrieved from https://books.google.com/books?hl=en\&lr=\&id=I6CZ6wpNKeEC\&oi=fnd\& pg=PA123\&ots=ujaHwtyK8O\&sig=N-te0BeTbB0IyV7aOmuwBAqwtCk

Hespos, S. J., \& Spelke, E. S. (2004). Conceptual precursors to language. Nature, 430(6998), 453-456.

Laurence, S., \& Margolis, E. (1999). Concepts and Cognitive Science. In E. Margolis \& S. Laurence (Eds.), Concepts: Core Readings (pp. 3-81). Cambridge, Mass: A Bradford Book.

Lupyan, G. (2009). Extracommunicative Functions of Language: Verbal Interference Causes Selective Categorization Impairments. Psychonomic Bulletin \& Review, 16(4), 711-718. https://doi.org/10.3758/PBR.16.4.711 Lupyan, G. (2012). What do words do? Towards a theory of languageaugmented thought. In B. H. Ross (Ed.), The Psychology of Learning and Motivation (Vol. 57, pp. 255-297). Waltham, MA: Academic Press. Retrieved from http://www.sciencedirect.com/science/article/pii/B9780123942937000078 